\section{FRI0205 COMPARISON OF WORK DISABILITY, DEPRESSION AND QUALITY OF LIFE IN PATIENTS WITH ANKYLOSING SPONDYLITIS VS. PSORIATIC ARTHRITIS: INTERIM RESULTS FROM THE COMPLETE STUDY}

M. Khraishi ${ }^{1}$, L. Bessette ${ }^{2}$, B. Haraoui ${ }^{3}$, B. Florica ${ }^{4}$, Y. Setty ${ }^{5}$, M. Teo ${ }^{6}$, V. Remple ${ }^{7}$ ${ }^{1}$ Memorial University of Newfoundland, St. John's; ${ }^{2}$ Laval University, Centre Hospitalier de l'Université Laval, Quebec; ${ }^{3}$ Centre Hospitalier de l'Université de Montréal, Montreal; ${ }^{4}$ University of Toronto, Toronto; ${ }^{5}$ Grey Bruce Health Services, Owen Sound; ${ }^{6}$ University of British Columbia, Penticton; ${ }^{7}$ AbbVie Corporation, Montreal, Canada

Background: Ankylosing Spondylitis (AS) and Psoriatic arthritis (PsA) are chronic progressive inflammatory diseases associated with severe pain and joint damage which may negatively impact patient reported outcomes (PRO), such as ability to work, depression and quality of life (QoL).

Objectives: To assess differences in PROs between patients with active AS and PsA requiring change in their treating regimen.

Methods: Patients eligible for the COMPLETE studies are anti-TNF $\alpha$ naîve adults, with active AS or PsA who require change in their regimen per the treating physician. Here, baseline data from patients enrolled between Jul/2011-Jun/2017 were included. PROs included the WLQ, BDI, and SF-12. Disease activity was classified as active/severe vs low/moderate based on BASDAI ( $\geq 4$ vs $<4$ ) for AS and based on DAS28 $(\geq 5.1$ vs $<5.1)$ for PsA. PsA patients were further stratified as per $\mathrm{BSA} \geq 3 \%$ vs $<3 \%$. Differences between AS and PsA in WLQ, SF-12, and $\mathrm{BDI}$ were assessed with multivariate generalised linear models.

Results: 528 AS and 317 PsA $(41 \%$ with BSA $>3 \%$ ) patients were included. Upon multivariate adjustment, AS patients showed a trend towards higher scores in the SF-12 Physical Functioning subdomain compared to PsA patients with BSA $<3 \%(p=0.069)$ at baseline (table 1$)$. Furthermore, PsA patients with $B S A \geq 3 \%$ had significantly higher scores in the SF-12 Role Functioning (Physical) subdomain $(\mathrm{p}=0.031)$ and showed a trend towards higher scores in the SF-12 Mental Health subdomain $(p=0.085)$ compared to those with $B S A<3 \%$. No differences were observed between groups in any of the remaining SF-12 subdomains, WLQ, or BDI.

In terms of other determinants of PROs, high/very high disease state was associated with significantly higher BDI and worse scores in all WLQ and SF-12 dimensions and female gender was found to be a significant predictor of higher BDI scores and lower scores in the SF-12 physical functioning, vitality, social functioning and mental health subdomains.

\begin{tabular}{|c|c|c|c|c|}
\hline Assesment & Parameter & $\begin{array}{c}\text { AS } \\
(n=528)^{*}\end{array}$ & $\begin{array}{c}\text { PsA w/BSA } \\
\geq 3 \% \\
(n=130)^{\star}\end{array}$ & $\begin{array}{c}\text { PsA w/BSA } \\
<3 \% \\
(n=187)^{*}\end{array}$ \\
\hline $\mathrm{BDI}$ & Total Score & 12.6 & 13.8 & 13.7 \\
\hline \multirow[t]{5}{*}{ WLQ } & Mental Interpersonal Demands & 24.9 & 27.2 & 26.7 \\
\hline & Output Demands & 29.8 & 32.8 & 34.7 \\
\hline & Physical Demands & 36.3 & 39.9 & 38.9 \\
\hline & Time Demands & 37.8 & 41.1 & 42.0 \\
\hline & Productivity Loss Score & 8.0 & 8.5 & 9.1 \\
\hline \multirow{10}{*}{ SF-12 } & General Health & 50.2 & 49.8 & 45.3 \\
\hline & Physical Functioning & 46.1 & 43.1 & 38.2 \\
\hline & Role Functioning (Physical) & 43.0 & 47.9 & 39.2 \\
\hline & Bodily Pain & 40.3 & 43.4 & 43.9 \\
\hline & Vitality & 36.2 & 38.4 & 33.6 \\
\hline & Social Functioning & 59.5 & 58.9 & 57.5 \\
\hline & Role Functioning (Emotional) & 64.4 & 63.0 & 57.9 \\
\hline & Mental Health & 56.7 & 58.6 & 52.2 \\
\hline & $\begin{array}{l}\text { Physical Component Summary } \\
\text { Scale }\end{array}$ & 24.6 & 24.7 & 24.6 \\
\hline & $\begin{array}{l}\text { Mental Component Summary } \\
\text { Scale }\end{array}$ & 18.9 & 18.9 & 18.8 \\
\hline
\end{tabular}

'Least square means adjusted for age, gender, disease duration, and disease activity. Conclusions: AS and PsA affect multiple aspects of patients' lives without significant differences between the two diseases. Higher disease severity is associated with depressive symptoms and greater impairment in daily activities and work productivity. The impact of disease activity and treatment response over time on PRO will be evaluated in future analyses.

REFERENCE:

[1] JSS Medical Research, Montreal, Canada.

Disclosure of Interest: M. Khraishi Consultant for: AbbVie, Speakers bureau: AbbVie, L. Bessette Consultant for: Amgen, BMS, Janssen, Roche, UCB, AbbVie,
Pfizer, Celgene, Lilly, Novartis, Speakers bureau: Amgen, BMS, Janssen, Roche, UCB, AbbVie, Pfizer, Merck, Celgene, Lilly, Novartis, B. Haraoui Grant/research support from: AbbVie, Amgen, BMS, Janssen, Pfizer, Roche, and UCB, Speakers bureau: Amgen, BMS, Janssen, Pfizer, and UCB, B. Florica: None declared, Y. Setty Consultant for: AbbVie, M. Teo Consultant for: AbbVie, Amgen, Celgene, Janssen, Merck, Novartis, Pfizer, Roche, Sanofi-Genzyme, Speakers bureau: AbbVie, Roche, V. Remple Shareholder of: AbbVie, Employee of: AbbVie DOI: 10.1136/annrheumdis-2018-eular.3800

\section{FRI0206 GENDER DIFFERENCES IN PATIENTS WITH AXIAL SPONDYLOARTHRITIS: RESULTS FROM THE ATLAS- 2017}

M. Garrido-Cumbrera ${ }^{1,2}$, D. Gálvez-Ruiz ${ }^{1}$, P. Zarco ${ }^{3}$, O. Braçe ${ }^{1}$, V. NavarroCompán ${ }^{4}$. ${ }^{1}$ Universidad de Sevilla, Sevilla; ${ }^{2}$ CEADE; ${ }^{3}$ Rheumatology, Foundation Hospital of Alcorcón; ${ }^{4}$ Rheumatology, Hospital Universitario La Paz, IdiPaz, Madrid, Spain

Background: Recent data suggest gender differences on clinical manifestations treatment access, and impact of the disease in patients with Axial Spondyloarthritis (axSpA). However, more data to confirm this hypothesis are needed.

Objectives: To assess gender differences on the physical, social, and psychological impact of the disease in patients with axSpA.

Methods: A sample of 680 axSpA patients was interviewed as part of the Spanish Atlas-2017 project. This aimed to promote early referral, improve healthcare, and the use of effective treatments in patients with axSpA. Among the recorded data the following variables were collected: sociodemographic, smoking habits, degree of functional limitation in 18 daily activities (0-3 none, little, some, moderate), spinal stiffness level at cervical, thoracic, and lumbar spine (0-3 none, little, some, moderate), disease activity through BASDAI (0-10), risk of severe psychiatric illness using General Health Questionnaire - GHQ-12 (0-12), treatment received (NSAIDs and biological therapy), and disability. Differences for all of these variables between patients who are part of support group associations (associatedpatients) and those who are not (non-associated patients) were tested using Mann-Whitney or Chi-square tests.

Results: In total, 323 (47.5\%) men and 357 (52.5\%) women participated in the survey. Compared with men, women reported a longer delay in diagnosis. Additionally, despite having a shorter disease duration, women reported significantly higher disease activity, worse functionality, and a higher risk of severe psychiatric illness than men. On the other hand, male patients had been treated more fre quently with biological therapies and were significantly more likely to have had their disability legally recognised.

Abstract FRI0206 - Table 1. Sociodemographic and clinical outcomes of the disease characteristics stratified for the patient gender

\begin{tabular}{|c|c|c|c|}
\hline & $\begin{array}{c}\text { Men } \\
\text { (mean } \pm \text { SD or } \\
\%)\end{array}$ & $\begin{array}{c}\text { Women } \\
\text { (mean } \pm \text { SD or } \\
\%)\end{array}$ & $P$ \\
\hline Age & $48.1 \pm 10.89$ & $43.40 \pm 10.29$ & $<0.001$ \\
\hline Marital Status (Married) & $76.5 \%$ & $66.9 \%$ & $<0.05$ \\
\hline Study Level (University) & $31.9 \%$ & $41.5 \%$ & $<0.01$ \\
\hline Smoker & $56 \%$ & $51.5 \%$ & 0.2 \\
\hline Patient Association Membership & $53.9 \%$ & $35.6 \%$ & $<0.001$ \\
\hline Diagnostic Delay & $7.85 \pm 7.02$ & $9.18 \pm 8.19$ & 0.07 \\
\hline Disease Duration & $23.98 \pm 12.48$ & $17.91 \pm 11.09$ & $<0.001$ \\
\hline HLA-B27 (Positive) ( $n=507)$ & $83.4 \%$ & $71.4 \%$ & 0.001 \\
\hline \multicolumn{4}{|l|}{ Treatment } \\
\hline - NSAIDs (without biology) & $26.9 \%$ & $32.5 \%$ & 0.1 \\
\hline - Biology (with or without NSAIDs) & $39.9 \%$ & $33.1 \%$ & $<0.06$ \\
\hline BASDAI $(n=442)$ & $5.10 \pm 2.14$ & $5.88 \pm 2.14$ & $<0.001$ \\
\hline Stiffness (High) $(n=540)$ & $44.4 \%$ & $29.2 \%$ & $<0.001$ \\
\hline $\begin{array}{l}\text { Functional Limitation }(0-54) \\
(\mathrm{n}=605)\end{array}$ & $24.63 \pm 13.10$ & $30.55 \pm 12.65$ & $<0.001$ \\
\hline GHQ-12 $(n=474)$ & $5.30 \pm 4.52$ & $6.19 \pm 4.41$ & 0.02 \\
\hline Inability to Work $(n=344)$ & $55.4 \%$ & $33.3 \%$ & $<0.001$ \\
\hline
\end{tabular}

Conclusions: Gender differences are observed regarding the impact of the dis ease in patients with axSpA. While women report a higher physical and psychological impact of the disease, men are more frequently legally recognised as disabled.

Acknowledgements: The Atlas was promoted by CEADE and funded by Novartis

Disclosure of Interest: None declared

DOI: 10.1136/annrheumdis-2018-eular.7136 